\title{
PERANCANGAN SISTEM PENGUKURAN KINERJA DENGAN METODE BALANCED SCORECARD (STUDI KASUS BUMD ABC KOTA BOGOR)
}

\author{
DESIGNING PERFORMANCE MEASUREMENT SYSTEM WITH BALANCED SCORECARD \\ (CASE STUDY OF ABC, A BOGOR CITY REGIONAL-OWNED COMPANY)
}

\author{
Deni Harumantaka ${ }^{* 1}$, Idqan Fahmi*), dan Agus Maulana**) \\ *) Sekolah Bisnis, IPB University \\ Jl. Pajajaran, Bogor 16151 \\ ${ }^{* *}$ Universitas Dr. Soetomo \\ Jl. Semmolowaru No. 84, Surabaya, Jawa Timur 6011
}

\begin{abstract}
Along with the implementation of provisions related to the regional-owned company in Bogor City Government, Regional Company ABC (the Company) took the initiative to design a precise and measurable performance measurement system. This study aims to manifest and portray the Company's vision, mission, and motto into strategic objectives, to determine key performance indicators, and to design a performance evaluation system based on Balanced Scorecard (BSC). Data were collected by structured questionnaires, interviews, and Focus Group Discussion (FGD) to the directors and structural management as respondents based on non-random sampling methods. The strategic analysis (i.e., SWOT matrix, external-internal matrix, QSPM) was employed to assess operational excellence, business growth, and customer loyalty as the company's strategic objectives. As a result, we found fourteen performance indicators for the Company based on the BSC. The indicator targets were in line with the Company's Budget Plan and the provisions of the Board of Directors. The design of this assessment system was then outlined in the form of an evaluation working paper as guidelines for the Company in running its business.
\end{abstract}

Keywords: balanced scorecard, performance, measurement, regional company, SWOT

\begin{abstract}
Abstrak: Seiring dengan penerapan ketentuan terkait perusahaan daerah di wilayah Pemerintahan Kota Bogor, BUMD ABC (Perseroan) berinisiasi untuk merancang sistem pengukuran kinerja yang tepat dan terukur. Penelitian ini bertujuan menerjemahkan dan memetakan visi, misi, dan moto Perseroan ke dalam tujuan strategis, menentukan indikator keberhasilan kinerja, dan merancang sistem penilaian kinerja Perseroan berdasarkan Balanced Scorecard (BSC). Data dikumpulkan melalui kuesioner terstruktur, wawancara, dan Diskusi Kelompok Terpumpun (DKT) dengan direksi dan pejabat struktural Perseroan menjadi responden penelitian melalui pengumpulan sampel tidak acak. Data kemudian diolah dengan alat analisis manajemen strategis (matriks SWOT, matriks internal eksternal, QSPM). Hasilnya adalah dalam proses perancangan dengan analisis, faktor keunggulan operasional, pertumbuhan usaha, dan loyalitas pelanggan menjadi tujuan strategis perusahaan yang ingin dicapai. Terdapat empat belas indikator kinerja yang tepat bagi Perseroan berdasarkan BSC dengan target yang selaras dengan RKAP dan ketentuan Dewan Direktur. Rancangan sistem penilaian ini kemudian dituangkan dalam bentuk kertas kerja evaluasi sebagai panduan bagi Perseroan dalam menjalankan bisnisnya.
\end{abstract}

Kata kunci: balanced scorecard, BUMD, kinerja, pengukuran, SWOT

\footnotetext{
${ }^{1}$ Corresponding author:

Email: deharuman@gmail.com
} 


\section{PENDAHULUAN}

Pendirian Badan Usaha Milik Daerah (BUMD) merupakan salah satu perwujudan upaya kemandirian daerah melalui optimasi sumber-sumber Pendapatan Asli Daerah (PAD). Oleh karenanya, pengelolaan yang baik dan bertanggungjawab mutlak diperlukan dalam ruang lingkup manajemen korporasi. Sebagai sebuah perusahaan, penetapan visi, misi, dan rencana bisnis yang baik oleh manajemen akan sangat mendukung pencapaian kinerja. Salah satu ukuran penilaian pencapaian kinerja yang sering digunakan adalah Balanced Scorecard (BSC). BSC selama ini teruji sebagai sebuah metode yang mampu menyelaraskan sasaran organisasi dan individu dengan strategi organisasi (Kaplan dan Norton, 1996).

BUMD ABC (Perseroan) merupakan perusahaan daerah yang bergerak dalam sektor manajemen pasar di wilayah Kota Bogor, Jawa Barat. Selama ini, ukuran kinerja BUMD-BUMD yang dimiliki Pemerintah Kota Bogor berpatokan kepada kinerja keuangan semata. Pada kenyataannya, setiap BUMD memiliki karakter bisnis yang berbeda-beda sehingga mengakibatkan sulitnya Pemerintah Kota Bogor untuk melakukan evaluasi kinerja pada tiap BUMD secara tepat dan proporsional sesuai karakter bisnisnya.

Pemerintah Kota Bogor pada tahun 2016 kemudian menginisiasi penerapan metode BSC untuk digunakan sebagai alat monitor dan evaluasi kinerja terhadap BUMD-BUMD di bawah pengawasannya. Sejalan dengan program Pemerintah Kota Bogor tersebut, sosialisasi berkaitan dengan BSC sudah dilakukan sejak tahun 2016 di lingkungan Perseroan, namun penerapannya belum dilakukan secara tepat dan terpadu. Manajemen Perseroan sendiri menganggap penerapan tersebut penting sebagai salah satu indikator keberlangsungan perusahaan tetap terjaga dalam waktu yang panjang.

Objektif dan ukuran-ukuran BSC berasal dari visi dan strategi suatu organisasi atau perusahaan yang terdiri dari empat ukuran perspektif yaitu: keuangan, pelanggan, proses bisnis internal, serta pertumbuhan dan pembelajaran (Kaplan dan Norton, 1996). Menurut Hladchenko (2015) dan Hansen \& Schaltegger (2016), BSC telah terbukti secara efisien dapat diimplementasikan dalam bisnis. BSC juga memiliki kelebihan seperti informasi kinerja perusahaan yang berimbang, horizon waktu evaluasi yang panjang, serta perusahaan cenderung untuk berjalan konsisten dengan strategi yang telah diterapkan (Kootanaee et al. 2013). BSC juga dapat diturunkan sampai kepada penilaian individual yang menjadi subjek sebagai penilaian kinerja (Chavan, 2009; Gholamhossein et al. 2018).

Dalam proses penyusunan sistem pengukuran kinerja, penggunaan beberapa alat analisis strategis banyak digunakan oleh perusahaan dalam melakukan perencanaan bisnisnya. Menurut Rangkuti (2016), dengan menggunakan analisis SWOT dan perspektif BSC akan diperoleh keseimbangan secara strategis antara target kinerja keuangan dengan target kinerja pelanggan, kinerja proses bisnis internal dan kinerja pembelajaran dan pertumbuhan. Penggunaan BSC digabungkan dengan analisis SWOT meruapakan alat analisis strategis yang cukup baik menghasilkan kerangka kerja strategi baru sebagai alat bantu manajemen untuk menentukan strategi yang akan dilakukan (Eftimov et al. 2016; Ayoubi et al. 2018).

Manajemen strategi merupakan hal yang penting karena dapat membantu menentukan kinerja jangka panjang dari suatu organisasi (Wheelen et al. 2015). Analisis SWOT menggambarkan kekuatan, kelemahan, peluang, dan ancaman. Formulasi strategi terdiri dari tiga tahapan dimulai dari masukan, pencocokan, dan keputusan (David, 2013), yang setiap tahapan memiliki alat ukur masing-masing seperti matriks internal IFE (Internal Factor Evaluation), matriks eksternal EFE (External Factor Evaluation), matriks internal eksternal (Internal External Matrix), matriks SWOT sampai kepada Quantitative Strategic Planning Matrix (QSPM).

Penggunaan BSC telah banyak diterapkan organisasi baik profit maupun non-profit di berbagai dunia, begitupun juga analisis SWOT sebagai alat pendukung keputusan strategis manajemen (Hagos dan Pal, 2010; Helm dan Nixon, 2010; Renwarin, 2017). Berkaca pada pengalaman di dunia, penggunaan BSC dengan menggunakan analisis SWOT banyak digunakan pada sektor publik di Spanyol (Manuel dan Lopez, 2010; Moullin, 2016). Penggunaan BSC pada perusahaanperusahaan di Taiwan secara statistik juga memiliki kelebihan karena mendorong peningkatan kinerja internal dan meningkatkan kepuasan pelanggan dibandingkan dengan yang tidak menggunakan BSC (Lin, 2015). Perusahaan-perusahaan di Amerika Serikat yang menggunakan BSC ternyata juga dipandang lebih inovatif dibandingkan dengan yang tidak 
menggunakan BSC (Zhang, 2016). Di Malaysia, BSC umum digunakan sebagai ukuran kinerja perusahaan milik pemerintah (Said, 2013).

Di Indonesia, penelitian terkait penerapan BSC di perusahaan telah banyak dilakukan. Wibowo (2014) melakukan penelitian pengukuran kinerja perusahaan milik daerah yang mempunyai fungsi selain memberikan pelayanan kepada masyarakat juga harus menghasilkan keuntungan di wilayah Kota Bogor. Hasilnya adalah penerapan BSC ternyata dapat menyeimbangkan antara fungsi pelayanan (fokus kepada pelanggan) dengan fungsi keuangan (fokus pada kinerja internal) dengan pelayanan pelanggan menjadi prioritas. Suhendi (2012) dan $\mathrm{Hu}$ et al. (2015) dalam penelitiannya menyebutkan bahwa pengukuran kinerja BSC dapat digabungkan dengan metode Analytic Network Process (ANP) untuk memperoleh prioritas hasil.

Secara umum, penelitian-penelitian yang dilakukan setidaknya menunjukkan dua poin penting. Pertama, penggunaan BSC telah terbukti secara empiris memudahkan manajemen untuk mengevaluasi sasaran strategis, menentukan prioritas, sekaligus juga meningkatkan kinerja perusahaan. Kedua, penggunaan BSC pada perusahaan juga dapat digabungkan dengan metode lain seperti analisis SWOT maupun ANP agar dapat mempertajam hasil yang diperoleh.

Terdapat tiga tujuan utama dari penelitian ini yang ingin dicapai. Pertama, menerjemahkan visi misi perusahaan dalam tujuan strategis. Kedua, menganalisis indikator keberhasilan kinerja yang tepat untuk perusahaan. Ketiga, merancang sistem penilaian kinerja berdasarkan metode BSC.

\section{METODE PENELITIAN}

Penelitian dilakukan di kantor Perseroan pada rentang periode waktu April 2017 hingga Februari 2018. Data primer dikumpulkan yang bersumber dari hasil kuesioner (self-administered), wawancara, dan DKT secara langsung. Teknik pengambilan sampel dilakukan secara tidak acak dengan convenience sampling terhadap direksi dan pejabat struktural di Perseroan. Irisan antara sumber data dan teknik pengambilan datanya disajikan sebagaimana Tabel 1 .

Konsep kerangka pemikiran yang dibangun dalam penelitian ini dimulai dari rumusan, peta, dan tujuan strategi Perseroan yang dijadikan sebagai basis dalam penentuan indikator kinerja utama berdasarkan konsep BSC yang dibagi dalam empat pilar. Setelah masing-masing indikator dalam empat pilar tersebut diidentifikasi, penentuan bobot serta target kemudian dilakukan agar rancangan sistem pengukuran kinerja yang komprehensif dapat terwujud. Hal tersebut menjadi inisiatif strategis bagi Perseroan dalam kapasitasnya sebagai perusahaan daerah.

Penggunaan alat analisis manajemen strategis pada penelitian ini dipilih karena dapat membantu menentukan kinerja jangka panjang dari suatu organisasi sebagaimana penelitian dari Van Looy \& Shafagatova (2016) dan Zehra \& Gedikoglu (2016). Data dan informasi yang diperoleh harus diolah terlebih dahulu agar dapat diterjemahkan ke dalam sebuah sistem manajemen strategi yang menggabungkan antara strategi perusahaan dengan BSC. Secara singkat, Gambar 1 menjelaskan tahapan dan proses pengolahan data serta teknik yang digunakan pada setiap tahapannya.

Matriks IFE dan EFE digunakan untuk mengevaluasi faktor-faktor utama dari kekuatan, kelemahan, ekonomi, politik, sosial, budaya, pemerintahan, demografi, lingkungan, hukum, persaingan, dan teknologi yang berdampak bagi Perseroan. Apabila total nilai tertimbang IFE dibawah 2,5 maka perusahaan tersebut lemah dari sisi faktor internalnya sedangkan apabila nilainya diatas 2,5 maka perusahaan tersebut memiliki kekuatan dari sisi faktor internalnya. Apabila total nilai tertimbang matriks EFE yang didapat kurang dari 2,5 artinya strategi perusahaan tidak dapat memanfaatkan peluang-peluang yang ada atau tidak dapat menghindar dari ancaman-ancaman eksternal yang terjadi. Apabila total nilai tertimbang lebih dari 2,5 mengindikasikan bahwa perusahaan berada pada strategi yang tepat untuk memanfaatkan peluang-peluang dan menghindari ancaman-ancaman yang berada dilingkungannya.

Tabel 1. Pengumpulan data dan sumbernya

\begin{tabular}{ll}
\hline Teknik & Objek penelitian \\
\hline Wawancara & $\begin{array}{l}\text { Dewan Direktur perusahaan, yang terdiri } \\
\text { dari Direktur Utama, Direktur Umum, dan } \\
\text { Direktur Operasional }\end{array}$ \\
& $\begin{array}{l}\text { Dewan Direktur perusahaan, yang terdiri } \\
\text { dari Direktur Utama, Direktur Umum, dan }\end{array}$ \\
& $\begin{array}{l}\text { Direktur Operasional } \\
\text { Kuesioner }\end{array}$ \\
& $\begin{array}{l}\text { Dewan Direktur, para Kepala Bagian } \\
\text { perusahaan }\end{array}$ \\
\hline
\end{tabular}




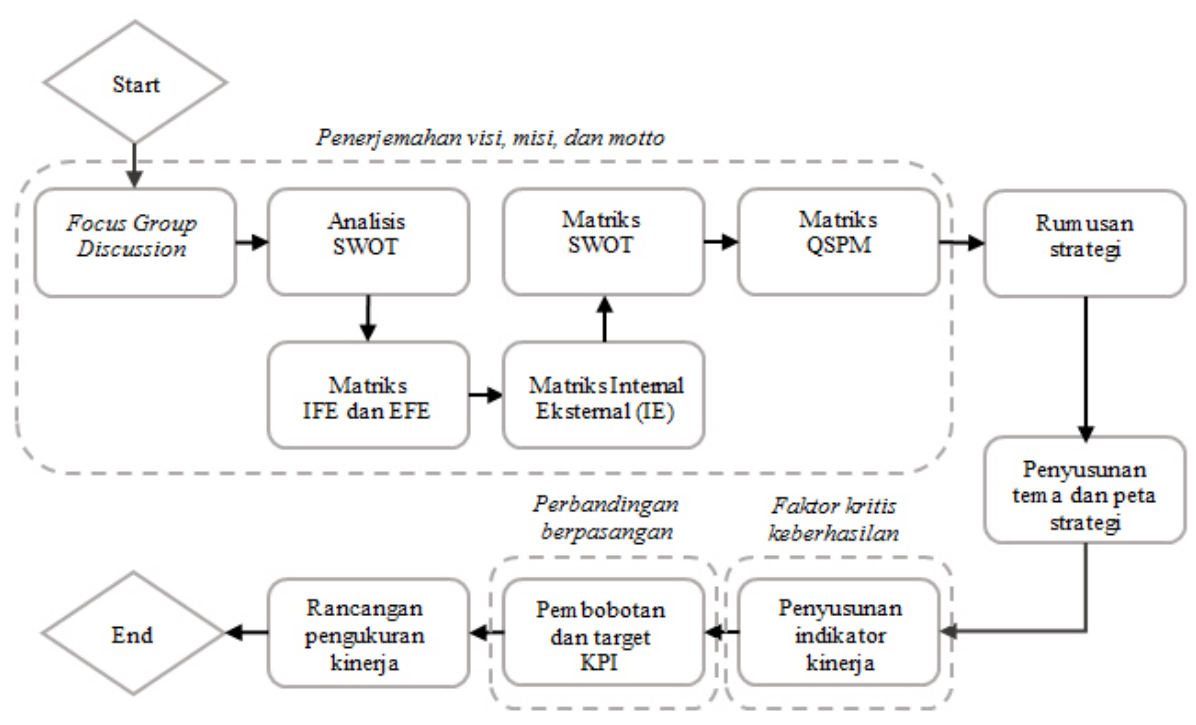

Gambar 1. Tahapan proses analisis data

Agar mengetahui lebih dalam strategi yang akan dijalankan, disusun Matriks Internal Eksternal (IE) berdasarkan dua dimensi yaitu nilai total tertimbang matriks IFE pada sumbu $X$ dan nilai total tertimbang matriks EFE pada sumbu Y. Apabila pada sumbu X, total nilai tertimbang yang didapat dari matriks IFE antara 1,0-1,99 menandakan lemah di posisi internal; 2,0-2,99 menandakan perusahaan berada di posisi rata-rata; 3,0-4,0 menandakan kuat di posisi internal. Begitu pula pada sumbu $\mathrm{Y}$ apabila total nilai tertimbang yang didapat dari matriks EFE antara 1,0-1,99 mengindikasikan rendah di posisi eksternal; 2,0-2,99 menandakan perusahaan berada di posisi pertengahan; 3,0-4,0 berarti tinggi di posisi eksternalnya.

Setelah mengetahui faktor-faktor yang mempengaruhi Perseroan, disusun matriks SWOT untuk menyusun strategi berdasarkan kekuatan (Strengths), kelemahan (Weaknesses), peluang (Opportunities), dan ancaman (Threats). Rumusan strategi alternatif yang mungkin dihasilkan sebagai berikut:

a) Strategi S-O: mengoptimalkan kekuatan untuk memanfaatkan peluang yang ada.

b) Strategi W-O: meminimalkan kelemahan untuk mendapatkan peluang.

c) Strategi S-T: mengoptimalkan kekuatan untuk meminimalisir ancaman yang terjadi.

d) Strategi W-T: meminimalkan kelemahan untuk menghindari ancaman yang terjadi.

\section{Quantitative Strategic Planning Matrix (QSPM)} digunakan untuk mengevaluasi rumusan-rumusan strategi secara objektif berdasarkan faktor-faktor internal dan eksternal yang sudah diketahui sebelumnya melalui matriks IFE, EFE, IE, dan SWOT. Komponenkomponen yang terdapat dalam QSPM adalah rumusanrumusan strategi, faktor-faktor internal dan eksternal, bobot, Attractiveness Scores (AS), Total Attractiveness Scores (TAS), serta penjumlahan dari total nilai daya tarik.

Setelah rumusan strategi didapat dari QSPM, selanjutnya dibuat tema strategi dengan tujuan memecahkan masalah yang terdapat dalam isu strategis disertai dengan cara mengukur target yang akan dituju. Kemudian dibuat tujuan strategi sebagai arah yang akan dituju oleh perusahaan dimasa yang akan datang dalam perspektif BSC. Setiap tujuan strategi pada perspektif BSC harus ditentukan faktor kritis keberhasilannya. Faktor kritis keberhasilan tersebut yang kemudian menjadi cikal bakal indikator kinerja utama atau Key Performance Indicator (KPI).

Setiap KPI kemudian diberi pembobotan yang proporsional sesuai visi dan misi perusahaan. Tujuan pembobotan iniuntuk menunjukkan tingkatkepentingan perusahaan dalam meningkatkan kinerjanya sehingga dapat menggunakan sumber daya secara tepat dan efisien untuk mencapai tujuan perusahaan. Pembobotan ini menggunakan metode perbandingan berpasangan (paired comparison). Rancangan sistem pengukuran kinerja perusahaan yang dihasilkan ini kemudian diberi nama company scorecard. 
HASIL

\section{Pemetaan Visi, Misi, dan Moto dalam Tujuan Strategis}

\section{Matriks Internal Eksternal dan Matriks SWOT}

Sebagai langkah awal, matriks IFE \& EFE dan analisis SWOT dilakukan melalui proses FGD dengan Dewan Direktur. Tahapan ini merupakan dasar yang penting dalam mengkapitalisasi faktor apa saja yang akan berdampak pada keberlangsungan perusahaan.

Terdapat masing-masing enam Strength dan delapan Weakness yang diindikasikan dapat berpengaruh kepada Perseroan sebagai faktor internal dan eksternal. Setelah faktor-faktor internal tersebut terkumpul, langkah selanjutnya adalah memberikan peringkat dan bobot. Faktor internal (1) satu-satunya BUMD Pasar Kota Bogor, memiliki bobot yang paling besar sehingga menjadikannya sebagai faktor Strength yang paling dominan. Sementara secara eksternal, faktor (1) fisik bangunan belum berstandar nasional, faktor (2) belum adanya sistem kontrol, dan faktor (7) pelatihan yang kurang menjadi faktor Weakness yang memiliki bobot paling tinggi secara bersamaan. Hasil evaluasi faktor internal secara lengkap dapat dilihat pada Tabel 2.
Selanjutnya, terdapat masing-masing empat Opportunity dan enam Threat yang diindikasikan dapat berpengaruh kepada Perseroan. Langkah selanjutnya adalah memberikan peringkat dan bobot. Faktor Opportunity pertumbuhan kota, memiliki bobot yang paling besar sehingga menjadikannya sebagai faktor peluang yang paling dominan. Faktor Threat kondisi politik, ekonomi, dan keamanan, memiliki bobot yang paling besar sehingga menjadikannya sebagai faktor Threat yang paling dominan. Hasil evaluasi faktor eksternal secara lengkap dapat dilihat pada Tabel 3.

Agar memperkuat hasil yang diperoleh, analisis Matriks IE digunakan untuk mengetahui posisi Perseroan saat ini dan menentukan strategi yang tepat. Matriks IE dibuat berdasarkan total nilai tertimbang yang dihasilkan oleh evaluasi faktor internal dan eksternal. Matriks IE terdiri dari dua sumbu yaitu sumbu horizontal yang merupakan total nilai tertimbang evaluasi internal (sebesar 2,81) dan sumbu vertikal yang merupakan total nilai tertimbang evaluasi eksternal (sebesar 2,94). Dari matriks ini diperoleh posisi Perseroan berada di wilayah 2 sel V yaitu sebagai perusahaan yang paling baik dikelola dengan strategi pertahankan dan pelihara. Hasil lengkap matriks ini dapat dilihat pada Gambar 2.

Tabel 2. Evaluasi faktor internal

\begin{tabular}{lccc}
\hline Variabel & Nilai & Bobot & Total \\
\hline Strength & & & \\
\hline Satu-satunya BUMD Pasar Kota Bogor & 3,80 & 0,11 & 0,41 \\
Kapasitas kelolaan pasar yang besar & 3,60 & 0,10 & 0,37 \\
Manajemen profesional & 3,60 & 0,10 & 0,37 \\
Kapasitas kios dan non-kios yang banyak & 3,60 & 0,10 & 0,37 \\
Sebelas potensi pendapatan & 3,20 & 0,09 & 0,29 \\
Compliance & 3,00 & 0,08 & 0,25 \\
\hline Weakness & & & \\
\hline Fisik bangunan belum berstandar nasional & 2,00 & 0,06 & 0,11 \\
Belum adanya sistem kontrol & 2,00 & 0,06 & 0,11 \\
Lemahnya data pedagang & 1,80 & 0,05 & 0,09 \\
Okupansi kios yang rendah & 1,80 & 0,05 & 0,09 \\
Belum adanya standardisasi kebersihan & 1,80 & 0,05 & 0,09 \\
Tarif pelayanan belum transparan & 1,80 & 0,05 & 0,09 \\
Pelatihan yang kurang & 2,00 & 0,06 & 0,11 \\
Belum adanya budaya perusahaan & 1,40 & 0,04 & 0,06 \\
\hline Total & & 1,00 & 2,81 \\
\hline
\end{tabular}


Tabel 3. Evaluasi faktor eksternal

\begin{tabular}{lccc}
\hline Variabel & Nilai & Bobot & Total \\
\hline Opportunity & & & \\
\hline Pertumbuhan kota & 3,80 & 0,14 & 0,52 \\
Pertumbuhan wisatawan & 3,00 & 0,11 & 0,32 \\
Kebijakan pemerintah terkait investasi & 3,40 & 0,12 & 0,41 \\
Peraturan daerah terkait BUMD & 3,60 & 0,13 & 0,46 \\
\hline Threat & & & \\
\hline Kondisi politik, ekonomi, dan keamanan & 2,80 & 0,10 & 0,28 \\
Pesatnya pertumbuhan pasar modern & 2,80 & 0,10 & 0,28 \\
Gangguan kamtib dan premanisme & 2,20 & 0,08 & 0,17 \\
Gangguan pedagang dan pembeli & 2,40 & 0,09 & 0,21 \\
Penurunan daya beli & 2,00 & 0,07 & 0,14 \\
Kebakaran pasar & 2,00 & 0,07 & 0,14 \\
\hline Total & & & 1,00 \\
\hline
\end{tabular}

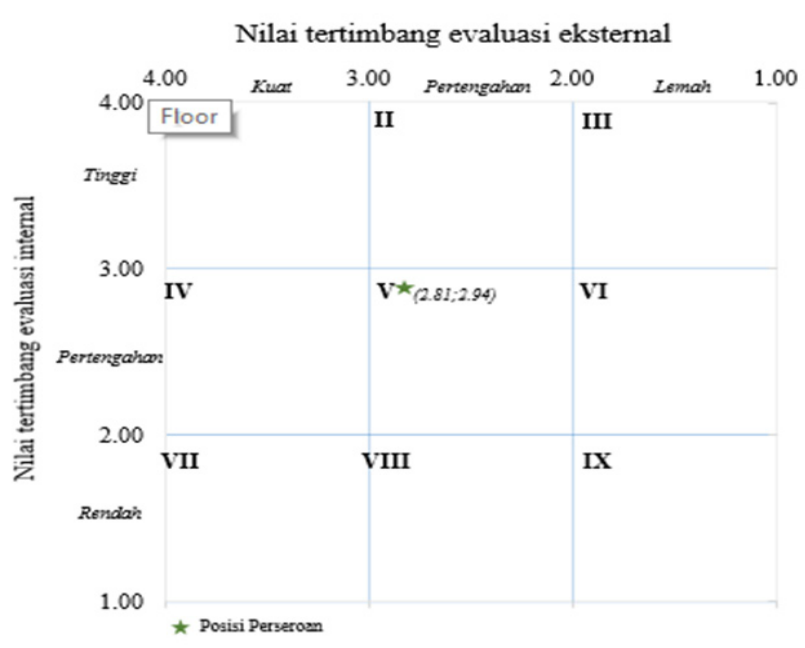

Gambar 2. Posisi Perseroan pada matriks internal eksternal

Untuk melihat kesesuaian strategi yang dihasilkan oleh Matriks IE yang didapatkan secara kuantitatif, diperlukan adanya analisis secara kualitatif berupa analisis matriks SWOT. Dari empat bagian strategi yang dihasilkan, yaitu Strength-Opportunity (S-O), Weakness-Opportunity (W-O), Strength-Threat (S-T), dan Weakness-Threat (W-T), Dewan Direktur Perseroan selanjutnya berdiskusi untuk menentukan strategi yang sejalan dengan strategi Matriks IE dan juga dapat menjawab isu-isu strategi yang sudah ditentukan sebelumnya. Strategi S-O selanjutnya dipilih sebagai alternatif strategi yang bisa dijalankan, yaitu mengoptimalisasi pendapatan, merevitalisasi pasar sesuai SNI dan kebutuhan masyarakat, bekerjasama dengan pihak investor, dan membuat atau memperbaiki SOP.

\section{Matriks QSPM}

Alat ini digunakan untuk memilih satu strategi diantara alternatif-alternatif strategi yang diperoleh masingmasing dari matriks IFE \& EFE dan matriks SWOT. DiantaraempatopsistrategiS-Oyaitu "mengoptimalisasi pendapatan", "merevitalisasi pasar sesuai SNI dan kebutuhan masyarakat", "bekerjasama dengan pihak investor", dan "membuat atau memperbaiki SOP", analisa QSPM menunjukkan bahwa dari strategi S-O yang mendapat nilai TAS terbesar adalah strategi "mengoptimalisasi pendapatan" dengan nilai TAS sebesar 5,03. Ini berarti bahwa Perseroan harus melakukan optimalisasi pendapatan di setiap unit pasar rakyat dan menjadi strategi utama dijalankan. Detail matriks QSPM dapat dilihat pada Tabel 4.

\section{Tema dan Peta Strategi}

Strategi S-O berupa "mengoptimalisasi pendapatan", "merevitalisasi pasar sesuai SNI dan kebutuhan masyarakat" serta "bekerjasama dengan pihak investor" merupakan bagian dari aktivitas operasional yang berdampak pada pertumbuhan usaha. Strategi "membuat kurikulum pelatihan pegawai" akan membuat pelayanan yang diberikan Perseroan semakin berkualitas yang akan menumbuhkan loyalitas pelanggan. Oleh karena itu, dibuat tiga tema strategi yaitu keunggulan operasional, pertumbuhan usaha, dan loyalitas pelanggan. 


\begin{tabular}{|c|c|c|c|c|c|c|c|c|c|}
\hline \multirow{3}{*}{ Faktor } & \multirow{3}{*}{ Bobot } & \multicolumn{8}{|c|}{ Alternatif Strategi } \\
\hline & & \multicolumn{2}{|c|}{$\begin{array}{l}\text { Mengoptimalisasi } \\
\text { pendapatan }\end{array}$} & \multicolumn{2}{|c|}{$\begin{array}{l}\text { Merevitalisasi } \\
\text { pasar }\end{array}$} & \multicolumn{2}{|c|}{$\begin{array}{c}\text { Bekerjasama } \\
\text { dengan investor }\end{array}$} & \multicolumn{2}{|c|}{$\begin{array}{c}\text { Membuat/ } \\
\text { memperbaiki } \\
\text { SOP }\end{array}$} \\
\hline & & $\mathrm{AS}$ & TAS & $\mathrm{AS}$ & TAS & AS & TAS & AS & TAS \\
\hline \multicolumn{10}{|l|}{ Opportunity } \\
\hline Pertumbuhan kota & 0,14 & 1,33 & 0,18 & 2,67 & 0,36 & 2,00 & 0,27 & 0,67 & 0,09 \\
\hline Pertumbuhan wisatawan & 0,11 & 1,33 & 0,14 & 2,67 & 0,29 & 2,00 & 0,21 & 0,67 & 0,07 \\
\hline Kebijakan pemerintah terkait investasi & 0,12 & 2,00 & 0,24 & 4,00 & 0,49 & 3,00 & 0,36 & 1,00 & 0,12 \\
\hline Peraturan daerah terkait BUMD & 0,13 & 3,67 & 0,47 & 2,00 & 0,26 & 1,00 & 0,13 & 3,33 & 0,43 \\
\hline \multicolumn{10}{|l|}{ Threat } \\
\hline Kondisi politik, ekonomi, dan keamanan & 0,10 & 4,00 & 0,40 & 2,00 & 0,20 & 1,00 & 0,10 & 3,00 & 0,30 \\
\hline Pesatnya pertumbuhan pasar modern & 0,10 & 2,00 & 0,20 & 4,00 & 0,40 & 3,00 & 0,30 & 1,00 & 0,10 \\
\hline Gangguan kamtib dan premanisme & 0,08 & 3,33 & 0,26 & 2,00 & 0,16 & 1,00 & 0,08 & 3,67 & 0,29 \\
\hline Gangguan pedagang dan pembeli & 0,09 & 3,33 & 0,29 & 2,00 & 0,17 & 1,00 & 0,09 & 3,67 & 0,31 \\
\hline Penurunan daya beli & 0,07 & 0,00 & 0,00 & 0,00 & 0,00 & 0,00 & 0,00 & 0,00 & 0,00 \\
\hline Kebakaran pasar & 0,07 & 0,67 & 0,05 & 2,00 & 0,14 & 1,33 & 0,10 & 2,67 & 0,19 \\
\hline Total & 1,00 & & & & & & & & \\
\hline \multicolumn{10}{|l|}{ Strength } \\
\hline Satu-satunya BUMD Pasar Kota Bogor & 0,10 & 4,00 & 0,41 & 2,00 & 0,21 & 1,00 & 0,10 & 3,00 & 0,31 \\
\hline Kapasitas kelolaan pasar yang besar & 0,10 & 2,67 & 0,26 & 1,33 & 0,13 & 0,67 & 0,06 & 2,00 & 0,19 \\
\hline Manajemen profesional & 0,10 & 0,00 & 0,00 & 0,00 & 0,00 & 0,00 & 0,00 & 0,00 & 0,00 \\
\hline Kapasitas kios dan non-kios yang banyak & 0,10 & 4,00 & 0,39 & 2,00 & 0,19 & 1,00 & 0,10 & 3,00 & 0,29 \\
\hline Sebelas potensi pendapatan & 0,09 & 4,00 & 0,35 & 2,00 & 0,17 & 1,00 & 0,09 & 3,00 & 0,26 \\
\hline Compliance & 0,08 & 3,00 & 0,24 & 2,00 & 0,16 & 1,00 & 0,08 & 4,00 & 0,32 \\
\hline \multicolumn{10}{|l|}{ Weakness } \\
\hline Fisik bangunan belum berstandar nasional & 0,06 & 2,00 & 0,12 & 4,00 & 0,24 & 3,00 & 0,18 & 1,00 & 0,06 \\
\hline Belum adanya sistem kontrol & 0,05 & 3,00 & 0,16 & 2,00 & 0,11 & 1,00 & 0,05 & 4,00 & 0,22 \\
\hline Lemahnya data pedagang & 0,06 & 3,33 & 0,20 & 2,00 & 0,12 & 1,00 & 0,06 & 3,67 & 0,22 \\
\hline Okupansi kios yang rendah & 0,06 & 4,00 & 0,24 & 2,00 & 0,12 & 1,00 & 0,06 & 3,00 & 0,18 \\
\hline Belum adanya standardisasi kebersihan & 0,06 & 0,00 & 0,00 & 0,00 & 0,00 & 0,00 & 0,00 & 0,00 & 0,00 \\
\hline Tarif pelayanan belum transparan & 0,05 & 4,00 & 0,19 & 2,00 & 0,10 & 1,00 & 0,05 & 3,00 & 0,15 \\
\hline Pelatihan yang kurang & 0,06 & 4,00 & 0,24 & 2,00 & 0,12 & 1,00 & 0,06 & 3,00 & 0,18 \\
\hline Belum adanya budaya perusahaan. & 0,04 & 0,00 & 0,00 & 0,00 & 0,00 & 0,00 & 0,00 & 0,00 & 0,00 \\
\hline Total & 1,00 & & 5,03 & & 4,13 & & 2,53 & & 4,28 \\
\hline
\end{tabular}

Dari setiap tema strategi kemudian dibuat tujuan strategis sebagai arah perusahaan dalam perspektifBSC. Tujuan-tujuan strategis tersebut kemudian digabungkan menjadi satu rangkaian yang saling berkaitan. Tujuan strategis yang telah disusun dan disepakati oleh Dewan Direktur Perseroan dapat dilihat pada Tabel 5.

Untuk memudahkan Direksi dalam menerapkan strategi berdasarkan BSC, akan dibentuk peta strategi sehingga dapat diketahui hal-hal utama, unggul, dan harus dicapai. Peta ini menggambarkan bagaimana Perseroan mengoptimalkan aset yang dimiliki menjadi hasil nyata dari sisi keuangan dan pelanggan. Peta strategis
Perseroan yang menggambarkan saling keterkaitan, sistematis, dan terintegrasi pada Gambar 3.

\section{Indikator Keberhasilan Kinerja}

Tahapan pertama dalam menyusun indikator kinerja utama adalah dengan mengidentifikasi terlebih dahulu faktor kunci kesuksesan Perseroan. Berdasarkan hasil diskusi dengan Dewan Direktur dan peta strategi yang telah dirancang, disusun faktor kunci kesuksesan Perseroan berdasarkan masing-masing perspektif BSC sebagaimana disampaikan pada Tabel 6 . 
Tabel 5. Tujuan strategis perseroan

\begin{tabular}{|c|c|c|c|}
\hline Perspektif & Keunggulan operasional & Pertumbuhan strategis & Loyalitas pelanggan \\
\hline Keuangan & Efisiensi biaya & Profit meningkat & Pendapatan meningkat \\
\hline Pelanggan & Kualitas pelayanan & Retensi pelanggan & $\begin{array}{l}\text { Kepercayaan pelanggan } \\
\text { meningkat }\end{array}$ \\
\hline \multirow[t]{2}{*}{ Proses bisnis internal } & Penggunaan teknologi & Produktivitas kios & Transparansi tarif \\
\hline & $\begin{array}{l}\text { Produktivitas sumber daya } \\
\text { manusia }\end{array}$ & & \\
\hline \multirow[t]{2}{*}{ Pembelajaran dan pertumbuhan } & $\begin{array}{l}\text { Penerapan sistem teknologi } \\
\text { informasi }\end{array}$ & Revitalisasi pasar & Perbaikan prosedur \\
\hline & Kapasitas SDM meningkat & & \\
\hline
\end{tabular}

Tabel 6. Faktor kunci kesuksesan Perseroan

\begin{tabular}{ll}
\hline Perspektif & Faktor kunci kesuksesan \\
\hline Keuangan & Profit meningkat \\
& Efisiensi biaya \\
& Pendapatan meningkat \\
Pelanggan & Kepuasan pelanggan meningkat \\
Proses bisnis internal & Produktivitas kios \\
& Produktivitas sumber daya manusia \\
Pembelajaran dan pertumbuhan & Revitalisasi pasar \\
\hline
\end{tabular}

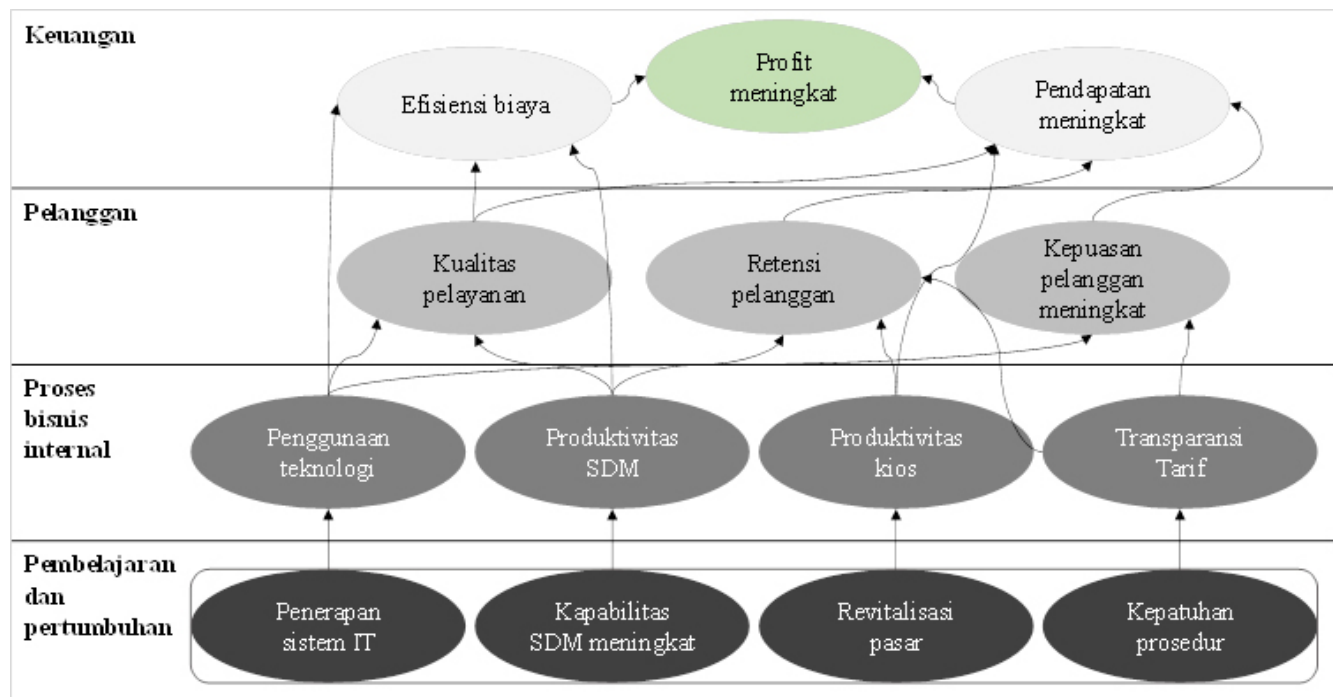

Gambar 3. Peta strategis Perseroan

Dari faktor kunci kesuksesan dan peta strategi yang telah dibuat, diformulasikan indikator kinerja utama Perseroan. Indikator-indikator ini akan menguraikan tujuan-tujuan strategis menjadi ukuran-ukuran kinerja yang ingin dicapai. Detail indikator kinerja utama dapat dilihat pada Tabel 7. Agar lebih mudah dipahami dan diimplementasikan, masing-masing indikator kinerja utama tersebut memiliki petunjuk teknis yang berisi definisi, rumus perhitungan kinerja, satuan, penentuan target, frekuensi pemantauan, sumber data kinerja, dan penanggungjawab kinerja.
Langkah selanjutnya adalah menentukan bobot dari masing-masing indikator kinerja utama tersebut sehingga dapat diketahui indikator mana yang harus menjadi perhatian utama. Pembobotan ini dilakukan dengan menggunakan metode perbandingan berpasangan. Dari hasil pengolahan data, didapat hasil perhitungan bobot untuk tingkat perspektif keuangan, pelanggan, proses bisnis internal, dan pembelajaran \& pertumbuhan masing-masing sebesar $0,448,0,185$, 0,221, 0,145. Pada bagian bobot untuk masing-masing indikator kinerja utama, lima bobot KPI yang tertinggi 
adalah laba bersih $(0,270)$, rasio kios $(0,133)$, indeks kepuasan pelanggan $(0,112)$, pendapatan per karyawan $(0,097)$ serta pasar yang telah direvitalisasi $(0,088)$.

Untuk setiap indikator kinerja yang telah tersusun, diperlukan adanya target yang harus mengacu kepada rencana bisnis Perseroan. Penyusunan target indikator kinerja ini mengacu kepada Rencana Kerja dan Anggaran Perusahaan dan berdasarkan keputusan Dewan Direktur mempertimbangkan situasi dan kondisi operasional perusahaan. Bobot dan target indikator kinerja utama dapat dilihat pada Tabel 8 .

\section{Rancangan Penilaian Kinerja}

Rancangan pengukuran kinerja merupakan kertas kerja berisi tabel yang mudah dibaca oleh pihak yang membutuhkan serta memuat informasi terkini yang sesuai dengan target. Rancangan ini perlu diformalkan dalam forum pemilik Perseroan (Pemerintah Kota Bogor) bersama Dewan Direktur sehingga menjadi dokumen resmikontrakmanajemen yang ditandatangani oleh Ketua Badan Pengawas dan Direktur Utama. Kontrak kinerja ini akan dievaluasi secara berkala dan diperbaharui sesuai dengan kondisi dan perkembangan Perseroan.

Dewan Direktur pada akhir masa periode tahunan kemudian akan memperoleh nilai akhir kinerja yang merupakan nilai rata-rata dari total nilai yang didapat pada setiap triwulannya. Terdapat empat kriteria penilaian akhir kinerja yang disepakati antara Badan Pengawas dan Direksi PD. ABC, yaitu Nilai yang didapat antara 0,90-1,00 artinya perusahaan berkinerja "istimewa"; Nilai yang didapat antara 0,70-0,89 artinya perusahaan berkinerja "baik sekali"; Nilai yang didapat antara 0,59-0,69 artinya perusahaan berkinerja "baik"; Nilai yang didapat kurang dari 0,59 artinya perusahaan berkinerja "cukup".

\section{Implikasi Manajerial}

Perancangan sistem penilaian kinerja memiliki implikasi bagi para pemangku kepentingan di lingkungan Perseroan. Bagi Direksi sebagai pembuat kebijakan strategi, sistem penilaian kinerja ini dapat memudahkan dalam pencapaian visi misi Perseroan termasuk mengontrol dan mengevaluasi kinerja seluruh pegawai secara objektif dan terukur. Bagi pegawai sebagai pelaksana program, sistem ini diharapkan dapat membuat pola kerja lebih terarah sesuai tugas dan fungsi serta lebih memotivasi karena penilaian lebih adil dan proporsional sesuai nilai kinerja yang diperoleh. Bagi Badan Pengawas sebagai perwakilan pemilik Perseroan, sistem ini akan memudahkan dalam mengontrol serta mengevaluasi kinerja Direksi secara terukur, periodik, dan mudah dimengerti.

Tabel 7. Indikator kinerja utama Perseroan

\begin{tabular}{lll}
\hline Perspektif & Tujuan strategis & Indikator kinerja utama \\
\hline Keuangan & Profit meningkat & Laba bersih \\
& Efisiensi biaya & Pengurangan biaya \\
Pelanggan & Pendapatan meningkat & Pendapatan \\
& Kepuasan pelanggan meningkat & Indeks kepuasan pelanggan \\
& Retensi pelanggan & Rasio retensi pelanggan \\
Proses bisnis internal & Kualitas pelayanan & Jumlah keluhan pelanggan \\
& Produktivitas kios & Rasio kios \\
& Produktivitas sumber daya manusia & Pendapatan per karyawan \\
& Transparansi tarif & Tarif di setiap pasar \\
& Penggunaan teknologi & Waktu rata-rata perbaikan fasilitas \\
Pembelajaran dan pertumbuhan & Revitalisasi pasar & Pasar yang telah direvitalisasi \\
& Kapabilitas SDM meningkat & Learning days \\
& Penerapan sistem IT & Penerapan sistem pelaporan \\
\hline
\end{tabular}


Tabel 8. Bobot dan target indikator kinerja utama

\begin{tabular}{llccc}
\hline Perspektif & Indikator kinerja utama & Bobot & Satuan & Target \\
\hline Keuangan & Laba bersih & 0,270 & Rupiah & 2.256 .646 .877 \\
& Pengurangan biaya & 0,059 & $\%$ & 20 \\
& Pendapatan & 0,062 & Rupiah & 32.379 .435 .221 \\
Pelanggan & Indeks kepuasan pelanggan & 0,112 & Skala likert (1-5) & 3 \\
& Rasio retensi pelanggan & 0,046 & $\%$ & 90 \\
& Jumlah keluhan pelanggan & 0,023 & $\%$ & 5 \\
Proses bisnis internal & Rasio kios & 0,133 & $\%$ & 80 \\
& Pendapatan per karyawan & 0,097 & Rupiah & 157.948 .464 \\
& Tarif di setiap pasar & 0,031 & Jumlah papan informasi & 10 \\
& Waktu rata-rata perbaikan & 0,025 & Jam & 3 \\
& fasilitas & & & \\
Pembelajaran dan pertumbuhan & Pasar yang telah direvitalisasi & 0,088 & $\%$ & 40 \\
& Learning days & 0,013 & Jam & 16 \\
& Penerapan sistem pelaporan & 0,023 & Set laporan & 192 \\
& Audit internal & 0,018 & Set laporan & 16 \\
\hline
\end{tabular}

\section{KESIMPULAN DAN SARAN}

\section{Kesimpulan}

Selaras dengan program Pemerintah Kota Bogor dan didorong oleh mandat pendirian, Perseroan merancang penerapan BSC sebagai alat evaluasi serta penilaian kinerja. Tujuannya tentu saja tidak hanya memberikan PAD kepada pemerintah daerah, namun juga terus memberikan keberlanjutan pelayanan terbaik kepada masyarakat.

Dalam rangka mencapai hal tersebut, proses penerjemahan visi dan misi dalam tujuan strategis dilakukan dengan serangkaian analisis dan diperoleh hasil bahwa Perseroan telah memanfaatkan kekuatan yang dimilikinya untuk menutupi kelemahannya serta mendapatkankeuntungandaripeluang-peluangeksternal dan dapat menghindari ancaman yang mungkin terjadi terhadap jalannya operasional perusahaan. Perseroan menilai faktor keunggulan operasional, pertumbuhan usaha, dan loyalitas pelanggan menjadi tujuan strategis perusahaan yang ingin dicapai.

Indikator kinerja yang tepat bagi Perseroan berdasarkan BSC adalah laba bersih, pengurangan biaya, pendapatan, indeks kepuasan pelanggan, rasio retensi pelanggan, jumlah keluhan pelanggan, rasio kios, pendapatan per karyawan, tarif di setiap pasar, waktu rata-rata perbaikan fasilitas, pasar yang telah direvitalisasi, learning days, penerapan sistem pelaporan, dan audit internal. Target yang digunakan mengacu kepada Rencana Kerja dan Anggaran Perusahaan (RKAP) serta target yang ditentukan oleh Dewan Direktur Perseroan.

Kertas kerja rancangan sistem penilaian kinerja Perseroan berdasarkan metode BSC kemudian disusun dan ditampilkan dalam bentuk tabel yang mudah dibaca oleh pihak yang membutuhkan. Rancangan ini kemudian perlu disetujui oleh Pemerintah Kota Bogor selaku pemilik Perseroan sebagai panduan bagi Perseroan dalam melakukan kegiatan bisnisnya.

\section{DAFTAR PUSTAKA}

Ayoubi M, Mehrabanfar E, Banaitis A. 2018. Guidelines on designing conceptual framework for strategic management with application to the energy industry. Administrative Sciences 8(3). https:// doi.org/10.3390/admsci8030027.

Chavan M. 2009. The balanced scorecard: a new challenge. The Journal of Management Development 28(5): 393-406. https://doi. org/10.1108/02621710910955930.

David FR. 2013. Strategic Management: Concepts and Cases. London: Pearson Education Limited.

Eftimov L, Trpeski P, Gockov G, Vasileva V. 2016. Designing a balanced scorecard as strategic management system for higher education institutions: a case study in macedonia. Ekonomika 62(2):29-48.https://doi.org/10.5937/ 
ekonomika1602029E.

Gholamhossein M, Nazari JA, Peivand G. 2018. The effects of knowledge creation process on organizational performance using the BSC approach: The mediating role of intellectual capital. Journal of Knowledge Management 22(4):802-823. https://doi.org/10.1108/JKM10-2016-0457.

Hagos TM, Pal G. 2010. The means of analysis and evaluation for corporate performances. Annales Universitatis Apulensis: Series Oeconomica 12(1): 438-449.

Hansen EG, Schaltegger S. 2016. The sustainability balanced scorecard: a systematic review of architectures. Journal of Business Ethics 133(2):193-221. https://doi.org/10.1007/ s10551-014-2340-3.

Helms MM, Nixon J. 2010. Exploring SWOT analysis - where are we now?. Journal of Strategy and Management 3(3): 215-251. https://doi. org/10.1108/17554251011064837.

Hladchenko, M. 2015. Balanced scorecard - a strategic management system of the higher education institution. The International Journal of Educational Management 29(2):167-176. https://doi.org/10.1108/IJEM-11-2013-0164.

Hu Y, Wen J, Yan Y. 2015. Measuring the performance of knowledge resources using a value perspective: Integrating BSC and ANP. Journal of Knowledge Management 19(6):1250-1272. https://doi. org/10.1108/JKM-10-2014-0431.

Kaplan RS, Norton DP. 1996. Translating Strategy into Action the Balanced Scorecard. Cambridge: The President and Fellows of Harvard College.

Kootanaee HJ, Kootanaee AJ, Hoseinian H, Talari HF. 2013. The balanced scorecard, alphabet of the modern management: from concept to implement. Advances in Management and Applied Economics 3(1): 47-59.

Lin H. 2015. Linking knowledge management orientation to balanced scorecard outcomes. Journal of Knowledge Management 19(6):12241249. https://doi.org/10.1108/JKM-04-20150132.

Manuel PR, Hernández AM, David OR. 2010. Implementing the balanced scorecard in public sector agencies: an experience in municipal sport services. Academia (45): 116.

Moullin M. 2016. Improving and evaluating performance with the public sector scorecard. International Journal of Productivity and Performance Management 66(4): 442-458. https://doi.org/10.1108/IJPPM-06-2015-0092.

Rangkuti F. 2016. SWOT Balanced Scorecard. Teknik Menyusun Strategi Korporat yang Efektif plus Cara Mengelola Kinerja dan Resiko. Jakarta: Gramedia.

Renwarin JMJ. 2017. The influence of aviation industrial environment and market orientation on competitive strategy and its effects on aviation business performance (study on aviation industry in Indonesia). Journal of Internet Banking and Commerce 22(3):1-23.

Said JM. 2013. The Implementation of Balanced Scorecard in a Malaysian Government Linked Company: An institutional perspective [tesis]. Manchester: University of Manchester.

Suhendi. 2012.Perancangan Sistem Pengukuran Kinerja MB-IPB Dengan Metode Balanced Scorecard [tesis]. Bogor: Institut Pertanian Bogor.

Van Looy A, Shafagatova A. 2016. Business process performance measurement: A structured literature review of indicators, measures and metrics. SpringerPlus 5(1):1-24. https://doi. org/10.1186/s40064-016-3498-1.

Wibowo AF. 2014. Analisis Kinerja PD. BPR (Bank Perkreditan Rakyat) Pasar Bogor Dengan Metode Balanced Scorecard [tesis]. Bogor: Institut Pertanian Bogor.

Wheelen TL, Hunger JD, Hoffman AN, Bamford CE. 2015. Strategic ManagementandBusiness Policy: Globalization, Innovation, and Sustainability. London: Pearson Education Limited.

Zehra KO, Gedikoglu T. 2016. Design principles for the development of the balanced scorecard. The International Journal of Educational Management 30(5):622-634. https://doi. org/10.1108/IJEM-01-2015-0005.

Zhang J. 2016. Empirical Evidence on the Use of the Balanced Scorecard and Innovation: Exploring the Role of Firm Competences and Performance Consequences [disertasi]. Ohio: University of Toledo. 